\title{
Ocorrência de anticorpos anti-Leishmania spp. em felinos em área endêmica do estado de São Paulo
}

\author{
[Occurrence of anti-Leishmania spp antibodies in felines in an endemic area of the \\ State of São Paulo] \\ V.M. Camprigher ${ }^{1}$, A.M.R.N. Matos ${ }^{1}$, F.P. Ferreira ${ }^{1}$, P.N. Batina ${ }^{2}$, \\ S.C. Costa ${ }^{3}$, I.T. Navarro ${ }^{3}$, M.S. Zanutto ${ }^{3}$ \\ ${ }^{1}$ Aluno de graduação - Universidade Estadual de Londrina - Londrina, PR \\ ${ }^{2}$ Médica veterinária - Laboratório Veterinário Laborcare - Bauru, SP \\ ${ }^{3}$ Universidade Estadual de Londrina - Londrina, PR
}

\author{
V.M. Camprigherl \\ https://orcid.org/0000-0001-8333-5807 \\ A.M.R.N. Matos1 \\ Attps://orcid.org/0000-0002-4095-2167 \\ F.P. Ferreira1 \\ https://orcid.org/0000-0003-0554-0252 \\ P.N. Batina2 \\ https://orcid.org/0000-0002-4374-2886 \\ S.C. Costa3 \\ https://orcid.org/0000-0002-3531-3555 \\ I.T. Navarro3 \\ https://orcid.org/0000-0001-9518-1083 \\ https://orcid.org/0000-0003-0880-4524
}

\section{RESUMO}

A leishmaniose visceral (LV) é uma zoonose de grande impacto em saúde pública. A infecção nos gatos tem sido relatada nos países onde a doença é endêmica. Seu papel como reservatório não está satisfatoriamente elucidado, embora a transmissão do parasito de um felino infectado para vetor tenha sido reportada por xenodiagnóstico. O objetivo do trabalho foi avaliar a presença de anticorpos antiLeishmania spp. em animais da espécie felina em área endêmica para LV (Bauru-SP), por meio dos testes sorológicos de reação de imunofluorescência indireta (RIFI) e ensaio imunoenzimático (ELISA), e associá-los às variáveis: gênero, idade, raça e forma de criação. Foram testados soros de 276 felinos, dos quais 82 foram reagentes pelo método ELISA (29,71\%), 17 pelo RIFI $(6,15 \%)$ e 10 em ambos os testes $(3,6 \%)$. Houve associação estatística significativa para a variável forma de criação, em que $100 \%$ dos animais errantes foram soropositivos a pelo menos um dos testes $(\mathrm{P}<0,005)$. Tal associação não foi encontrada para as demais variáveis analisadas $(\mathrm{P}>0,05)$. Não houve concordância entre o resultado dos testes, pois o método ELISA é mais sensível que o método RIFI.

Palavras-chave: gato, leishmaniose, sorodiagnóstico, RIFI. ELISA

\begin{abstract}
Visceral leishmaniasis $(V L)$ is a zoonosis with a great impact on public health. Infection in cats has been reported in countries where the disease is endemic. Its role as reservoir is not satisfactorily elucidated, although transmission of the parasite from an infected feline to vector has been reported by xenodiagnosis. The objective of this study was to evaluate the presence of anti-Leishmania spp antibodies in feline animals in an area endemic to LV (Bauru-SP), using the serological tests of Indirect Immunofluorescence Reaction (IFR) and ELISA and variables: gender, age, race and form of creation. Samples of 276 felines were tested, of which 82 were ELISA reagents (29,71\%), 17 by IFR (6,15\%) and 10 in both tests (3,6\%). There was a significant statistical association for the variable form of breeding, where $100 \%$ of the wandering animals were seropositive to at least one of the tests $(P<0,005)$. Such association was not found for the other variables analyzed $(P>0,05)$. There was no concordance between the results of the tests, since the ELISA method is more sensitive than the RIFI method.
\end{abstract}

Keywords: cat, leishmaniasis, serodiagnosis, RIFI. ELISA

\section{INTRODUÇÃO}

As leishmanioses são enfermidades infecciosas causadas por diferentes espécies de protozoários do gênero Leishmania. O Brasil é o país da

Recebido em 16 de outubro de 2017

Aceito em 26 de março de 2018

E-maill: val_vet@hotmail.com
América Latina com o maior número de casos anuais registrados, sendo a região Nordeste considerada a principal zona endêmica da leishmaniose visceral nas Américas (Brasil, 2017). Tem sido apontada como doença reemergente em evidente processo de transição epidemiológica, com aumento de casos nas áreas 
endêmicas e a expansão geográfica para estados da região Sul do Brasil, em franco processo de urbanização (Brasil, 2014). No Brasil, nas regiões consideradas endêmicas, a prevalência da leishmaniose felina encontrada variou bastante tanto na RIFI como no ELISA (Costa et al., 2010). Inquéritos epidemiológicos realizados em vários países têm demonstrado taxas preocupantes de infecção nos gatos domésticos (Cardoso et al., 2010; Garrido, 2012; Chatzis et al., 2014).

Os felinos são naturalmente infectados pelas mesmas espécies de Leishmania que afetam os cães e os humanos em áreas tropicais e subtropicais em todo o mundo (Pennisi e Persichetti, 2018). A transmissão do parasito de um gato infectado para o flebotomíneo já foi confirmada por xenodiagnóstico (Maroli et al., 2007). Estudos apontam a possibilidade de o gato ser considerado reservatório, tendo, assim, papel fundamental na epidemiologia dessa zoonose (Brianti et al., 2017). A justificativa do trabalho é alertar os médicos veterinários para a importância da leishmaniose visceral na espécie felina e para que a insiram na lista de seus diagnósticos diferenciais. O objetivo do trabalho foi avaliar a ocorrência de anticorpos antiLeishmania spp. em felinos de região endêmica (Bauru-SP) pelas técnicas sorológicas de RIFI e ELISA, em 2015.

\section{MATERIAL E MÉTODOS}

O trabalho foi aprovado pela Comissão de Ética no Uso de Animais (Ceua), com o protocolo de $\mathrm{n}^{\circ}$ 5912.2016.17, englobando a produção, manutenção e/ou utilização de animais, para fins de pesquisa científica.

O local de estudo foi o município de Bauru, estado de São Paulo, região considerada endêmica para leishmaniose visceral.

Foram disponibilizadas amostras de soros de 276 felinos de Bauru, formadas por 140 fêmeas e 136 machos; entre dois meses e 18 anos de idade, agrupadas em: quatro meses a um ano, dois a sete anos, oito a 13 anos, 14 a 18 anos, e não informada; 55 animais de raça e 221 sem raça definida (SRD); 258 domiciliados (cinco animais residentes em apartamento e 253 em casas térreas) e 18 errantes. A divisão em faixas etárias foi realizada aleatoriamente, em razão da grande diferença de idade entre os felinos. Não foi realizado cálculo sobre o $\mathrm{n}$ amostral (amostra por conveniência), e todos os soros foram obtidos de proprietários, cujo poder aquisitivo permitiu que os felinos passassem por prévio atendimento veterinário.

Tais amostras foram encaminhadas por médicos veterinários da cidade para análise no laboratório veterinário Laborcare. Posteriormente, foram enviadas ao Laboratório de Zoonoses do Departamento de Medicina Veterinária Preventiva do Centro de Ciências Agrárias da Universidade Estadual de Londrina e submetidas aos exames sorológicos de reação de imunofluorescência indireta (RIFI) e ensaio imunoenzimático (ELISA) para pesquisa de anticorpos anti-Leishmania. Os gatos foram identificados e rastreados para análise de seus dados cadastrais (gênero, raça, idade e forma de criação) no laboratório.

O antígeno solúvel de $L$. amazonensis foi preparado de acordo com a metodologia descrita por Szargiki et al. (2009), com modificações. Após quatro dias de incubação das formas promastigotas em meio líquido Brain Heart Infusion - BHI (Himedia, India) e meio sólido Blood Agar Base - BAB (Himedia, India), a $24^{\circ} \mathrm{C}$, a cultura foi lavada com salina $0,9 \%$ de $\mathrm{NaCl}$ e centrifugada durante 10 minutos a $1000 \mathrm{x}$ $\mathrm{G}$, três vezes. $\mathrm{O}$ sedimento foi ressuspendido em $10 \mathrm{~mL}$ de salina a $0,3 \%$ de $\mathrm{NaCl}$ e submetido a seis ciclos rápidos de congelamento em nitrogênio líquido e descongelamento em banhomaria a $37^{\circ} \mathrm{C}$, seguido por seis ciclos de ultrassom (modelo FB120 - Fisher Scientific, USA) de 0,5 minuto, a $60 \mathrm{~Hz}$, a $30 \%$ de potência, em banho de gelo. Foi realizada a centrifugação (16.000 x $g, 30$ minutos, $4^{\circ} \mathrm{C}$ ), o sobrenadante foi coletado e a concentração proteica foi determinada por meio do kit Pierce BCA Protein Assay (Thermo Fisher Scientific, USA), conforme recomendações do fabricante. As alíquotas foram armazenadas em freezer a $-20^{\circ} \mathrm{C}$ até o momento da sua utilização.

Para realização da RIFI, utilizaram-se lâminas com antígeno bruto solúvel de L. amazonensis. Anticorpos anti-Leishmania foram detectados usando-se as diluições de 1:20, 1:40, 1:80, 1:160, $1: 320$ e 1:640. Os soros controle positivo e negativo empregados em todas as lâminas eram 
oriundos de gatos das cidades de Ilha Solteira e Londrina, respectivamente. Para a leitura das lâminas, utilizou-se microscópio de epifluorescência LEICA DMLB, no aumento 400x. Foram considerados positivos os resultados de fluorescência igual ou superior a 1:40 (Guimarães et al., 1974; Marzochi et al., 1980).

O ensaio imunoenzimático indireto (ELISAi) para felinos foi realizado de acordo com técnica descrita previamente por Paranhos-Silva et al. (1996), com adaptações. As microplacas foram sensibilizadas com antígeno de Leishmania amazonensis, na concentração de $2,5 \mu \mathrm{g} / \mathrm{mL}$, os soros e o conjugado foram diluídos a 1:100 e 1:5.000, respectivamente, em solução de caseína. Todas as placas apresentavam dois controles positivos, quatro controles negativos e um branco. O cálculo do cut-off de cada placa foi obtido pela média das absorbâncias dos soroscontrole negativos, com exclusão da média do branco, adicionado de três desvios-padrão. Após

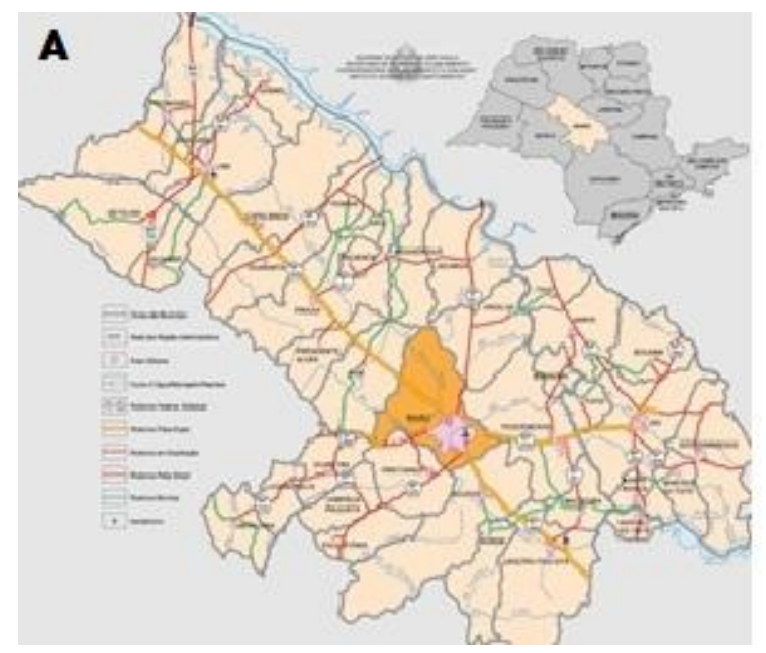

determinação do cut-off por placa, realizou-se a correção dos pontos de corte, para que a sensibilidade e a especificidade fossem otimizadas; para isso, foi construída a curva $R O C$ utilizando-se o MedCalc Statistical Software, no qual se obteve um cut-off de 0,247.

Para identificação dos fatores de risco (gênero, raça, idade, forma de criação) associados à variável resposta (resultados dos exames), utilizou-se o modelo de regressão logística e o seu ajuste foi verificado por meio do gráfico de envelope simulado (half-normal plot). Ainda foi aplicado o teste de McNemar para verificar a concordância entre os testes RIFI e ELISA.

\section{RESULTADOS E DISCUSSÃO}

Na Fig. 1A, é possível verificar a localização da cidade de Bauru, dentro do estado de São Paulo e, na 1B, a localização dos domicílios de felinos sororreagentes aos testes ELISA e/ou RIFI em Bauru, no ano de 2015.

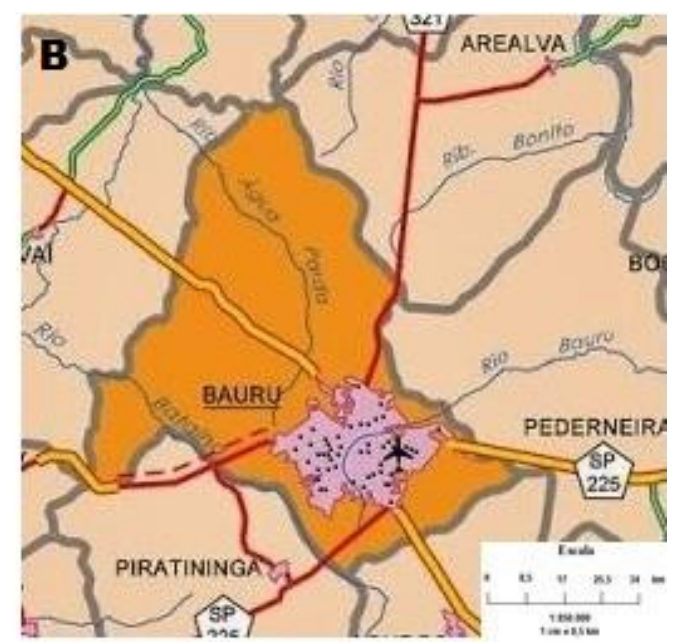

Figura 1A. Microrregião de Bauru, do estado brasileiro de São Paulo. 1B. Domicílio dos felinos sororreagentes aos testes ELISA e/ou RIFI em Bauru (2015).

Fontes: Fig. 1A - Região Administrativa de Bauru (2016). B - DER (Departamento de Estradas de Rodagem), 2006. Modificada pelo autor (2015).

Oitenta e dois animais $(29,71 \%)$ foram reagentes no ELISA, 17 (6,15\%) na RIFI e $10(3,6 \%)$ em ambos os testes (RIFI e ELISA). Pelo método RIFI, foram obtidos títulos de 1:80 em três amostras, uma amostra com título de 1:320 e outra com título de 1:640. Não houve associação estatística entre soropositividade e gênero, raça e idade $(\mathrm{P}>0,05)$, entretanto foi encontrada associação com forma de criação dos animais $(\mathrm{P}<0,05)$. Abaixo, a Tab. 1 com os resultados. 


\section{Camprigher et al.}

Tabela 1. Resultados da análise para determinação dos fatores de risco para LVF, pelos métodos sorológicos RIFI e ELISA, no município de Bauru, no ano de 2015

\begin{tabular}{ccccc}
\hline \multirow{2}{*}{$\begin{array}{c}\text { Fatores de } \\
\text { risco }\end{array}$} & Total de animais & \multicolumn{2}{c}{ Testes RIFI/ELISA } \\
\cline { 4 - 5 } Gênero & Machos & 136 & $58(42,65)$ & Positivos $(\%)$ \\
& Fêmeas & 140 & $51(36,42)$ & $89(57,35)$ \\
Raça definida & Com & 55 & $15(27,27)$ & $40(72,73)$ \\
& Sem & 221 & $94(42,53)$ & $127(57,47)$ \\
& 4 meses - 1 ano & 24 & $5(20,83)$ & $19(79,17)$ \\
Idade & $2-7$ anos & 92 & $36(39,13)$ & $56(60,87)$ \\
& $8-13$ anos & 76 & $30(39,47)$ & $46(60,53)$ \\
& $14-18$ anos & 51 & $29(56,86)$ & $22(43,14)$ \\
Forma de & Não informada & 33 & $18(54,55)$ & $15(45,45)$ \\
criação & Domiciliado & 258 & $91(35,27)$ & $167(64,73)$ \\
\hline
\end{tabular}

Trabalhos publicados em todo o mundo sugerem que a resposta imune celular da espécie felina é efetiva o suficiente para controlar e conferir certo grau de resistência natural à infecção por $L$. infantum. Assim, a espécie é considerada menos susceptível quando comparada à espécie canina, exceto nos casos em que ocorrem eventos imunossupressores, que propiciam a disseminação e visceralização do parasito (Solano-Gallego et al., 2007). Espera-se, então, que o número de gatos infectados, com altos títulos de anticorpos e sinais clínicos, seja bem menor que o de cães (Solano-Gallego et al., 2007).

Os métodos sorológicos são os mais utilizados para o diagnóstico de leishmaniose visceral canina (LVC) (Manual..., 2008). Nos cães, altos títulos de anticorpos indicam infecção ativa e potencial transmissão do protozoário para os vetores (Quinnell et al., 2003). No entanto, estudos demonstraram que tal fato não ocorre nos gatos (Simões-Mattos et al., 2005; MartínSánchez et al., 2007).

Neste trabalho, 6,15\% dos gatos foram reagentes pela técnica de RIFI. Alguns autores encontraram valores maiores (Vita et al., 2005; Martín-Sánchez et al., 2007; Garrido, 2012; Chatzis et al., 2014; Caldart et al., 2016). Entretanto, outros autores encontraram valores menores (Montoya et al., 2018). Pelo método ELISA, 29,71\% dos animais foram reagentes. Caldart et al. (2016) obtiveram valores maiores de frequência, enquanto outros autores encontraram valores menores (Solano-Gallego et al., 2007; Cardoso et al., 2010; Costa et al., 2010; Chatzis et al., 2014). Observou-se que, assim como no presente trabalho, os autores que realizaram os dois métodos sorológicos obtiveram maior soropositividade no ELISA quando comparado à RIFI (Caldart et al., 2016), visto que o método ELISA é mais sensível que a RIFI.

Alguns trabalhos corroboram a falta de correlação existente entre testes sorológicos entre si e com os testes moleculares ou reações em cadeia de polimerase (PCR) (Can et al., 2016; Montoya et al., 2018). Martín-Sánchez et al. (2007) encontraram alta proporção de animais positivos na PCR de sangue $(31,6 \%)$ e com baixos títulos de anticorpos pela RIFI (20) e baixa positividade na PCR de sangue em animais com altos títulos de anticorpos (160). SimõesMattos et al. (2005) e Can et al. (2016) afirmaram que não existe correlação entre infecção e produção de anticorpos nos felinos, pois estes tornam-se soropositivos somente na fase tardia da infecção.

No presente trabalho, foi encontrada falta de correlação entre os métodos sorológicos avaliados $(\mathrm{P}<0,0001)$. A porcentagem de felinos soropositivos foi muito maior pela técnica de ELISA que pela RIFI, assim como encontrados por outros autores (Caldart et al., 2016). Abaixo, a Tab. 2 compara o resultado entre os dois métodos sorológicos realizados entre si e isoladamente. 
Tabela 2. Valores absolutos e relativos dos resultados dos testes sorológicos isoladamente e entre si

\begin{tabular}{cccc}
\hline Exames & RIFI & ELISA & RIFI e ELISA \\
\hline Positivo & $17(6,15 \%)$ & $82(29,71 \%)$ & $10(3,6 \%)$ \\
Negativo & $259(93,85 \%)$ & $194(70,29 \%)$ & $266(96,4 \%)$ \\
Total & $276(100 \%)$ & $276(100 \%)$ & $276(100 \%)$ \\
\hline
\end{tabular}

Legenda: RIFI - reação de imunofluorescência indireta; ELISA - ensaio imunoenzimático.

$\mathrm{Na}$ espécie canina, as duas técnicas sorológicas são recomendadas pelo Ministério da Saúde (Brasil, 2014) para avaliação da soroprevalência em inquéritos caninos amostrais e censitários; o ELISA para a triagem e a RIFI para a confirmação dos cães sororreagentes ao teste ELISA. Tal procedimento pode ser estendido à espécie felina. Assim, no presente trabalho, foram considerados como infectados somente os gatos reagentes em ambos os testes.

Resultados falso-positivos podem ocorrer por reação cruzada com Toxoplasma spp., Trypanosoma spp. e Ehrlichia spp. (Chatzis et al., 2014; Noé et al., 2015). Os protozoários causadores da doença de Chagas, assim como a Leishmania spp., também pertencem à família Trypanosomatidae e compartilham vários antígenos que ocasionam reações cruzadas em diagnósticos sorológicos (Caldart et al., 2016). Contudo, razões técnicas também podem levar a erros. Importante lembrar que procedimentos de coleta, processamento, transporte e/ou armazenamento indevidos podem ocasionar hemólise e consequente coloração avermelhada do soro, interferindo na absorbância de métodos colorimétricos (Bastos et al., 2010), como o ELISA.

No método RIFI, a interpretação pode ser subjetiva. Neste estudo, nas baixas diluições dos soros a serem testados, resíduos de fluoresceína foram confundidos com fluorescência citoplasmática do parasito.

Não existe um método de RIFI padronizado para gatos nem um valor de título de anticorpo aceito universalmente que corresponda à infecção. Os validados em cães são utilizados nos gatos (Can et al., 2016).

A especificidade e a sensibilidade dos exames realizados poderiam aumentar se, em vez de promastigotas, fossem utilizadas as formas amastigotas, pois estas são as formas que parasitam o hospedeiro vertebrado. Embora as amastigotas possam ser utilizadas como antígenos, as promastigotas representam a forma de antígeno mais frequentemente utilizada (Manual..., 2008).

Não houve associação estatística em relação ao gênero $(\mathrm{P}>0,05)$, como foi também observado por Garrido (2012). No entanto, Cardoso et al. (2010) e Montoya et al. (2018) encontraram predomínio de machos felinos sororreagentes. Estes associaram o observado ao comportamento do macho, tanto na disputa por território quanto por fêmeas para acasalamento. Por outro lado, Costa et al. (2010) obtiveram predomínio de soropositividade em fêmeas.

Não houve associação estatística entre a soropositividade e a idade dos animais $(\mathrm{P}>0,05)$ (Tab. 1), como observado por outros autores (Solano-Gallego et al., 2007; Montoya et al., 2018); ao contrário de Costa et al. (2010) e Cardoso et al. (2010), que observaram predomínio em gatos adultos e idosos, respectivamente. Animais idosos adoecem com maior frequência quando comparados aos mais jovens (Garrido, 2012), e proprietários de gatos não visitam clínicos veterinários rotineiramente, quando comparados aos dos cães, pelo menos em países em desenvolvimento, onde a leishmaniose é endêmica (Simões-Mattos et al., 2005). Otranto et al. (2017) afirmaram que o maior número de animais idosos soropositivos poderia ser explicado pela exposição cumulativa ocorrida ao longo da vida.

Assim como Garrido (2012), não se observou associação estatística para o fator raça $(\mathrm{P}>0,05)$. Navarro et al. (2010) verificaram que a raça felina Europeu Comum foi mais acometida que as demais. Entretanto, faz-se necessário verificar se realmente há predisposição racial ou se a referida raça é muito comum na localidade estudada. Solano-Gallego et al. (2000), em ensaio realizado na ilha de Maiorca (Espanha), observaram que o Ibizian é uma raça canina 
geneticamente resistente por apresentar resposta imune do tipo celular.

Em relação à forma de criação, encontrou-se associação estatística entre gatos domiciliados e errantes $(\mathrm{P}>0,05)$. Dos 18 animais errantes, quatro foram positivos nos dois testes e 14 pelo método ELISA. Contudo, é importante ressaltar que não foram obtidas informações a respeito da quantidade de animais e da frequência com que os gatos domiciliados tinham acesso à rua. Já Cardoso et al. (2010) e Garrido (2012), em Portugal, não encontraram tal associação.

Vita et al. (2005), em seus estudos, observaram que $85 \%$ dos felinos sororreagentes eram errantes ou com acesso ao exterior dos domicílios. Cardoso et al. (2010) encontraram diferença significativa, pelo método ELISA, entre gatos de área urbana $(0 \%)$ e rural $(10,5 \%)$ de município na região norte de Portugal. Encontraram-se $29,71 \%$ pelo mesmo método em área urbana, diferença possivelmente associada a resultados falso-positivos (Chatzis et al., 2014). Entretanto, pelo método RIFI, encontraram-se $6,15 \%$ de animais reagentes. Esses dados sugerem uma maior prevalência de leishmaniose felina no município de Bauru como um todo, já que não foram analisadas amostras de soros de gatos domiciliados na zona rural. Noé et al. (2015) sugerem que os gatos domésticos podem atuar como elo entre ambientes silvestres e domésticos ao se deslocarem para áreas periurbanas e rurais, o que favorece a disseminação do parasito devido à maior exposição ao vetor. É sabido que o repasto sanguíneo, realizado pela fêmea do flebotomínio, pode ocorrer em diferentes espécies (Desjeux, 2004). Barata et al. (2005) observaram forte preferência do vetor por sangue de aves domésticas, embora não exista na literatura relato dessa espécie exercendo papel de reservatório para L. infantum.

Comportamentos típicos dos felinos podem favorecer a disseminação do parasito nessa espécie, sobretudo no que se refere ao acesso à rua, onde exercem atividade predatória, percorrem grandes distâncias, coabitam com reservatórios silvestres e sinantrópicos, reforçados ainda pelo hábito noturno, similar ao dos flebotomíneos (Desjeux, 2004).
Novas e continuadas pesquisas devem ser realizadas, a fim de se elucidar o verdadeiro papel do gato na epidemiologia da doença para que medidas cabíveis em saúde pública sejam tomadas com relação à espécie.

\section{CONCLUSÃO}

Demonstrou-se a ocorrência de anticorpos antiLeishmania spp. nos felinos da cidade de Bauru, estado de São Paulo, área endêmica para LVC. Não houve concordância entre os testes utilizados, já que o ELISA é mais sensível que a RIFI. Não houve associação estatística relacionada à idade, ao gênero e à raça. Porém, não se pode descartar a importância desses fatores de risco, já que o $\mathrm{n}$ amostral não representou a população felina da cidade de Bauru e as amostras foram de conveniência. Houve associação estatística relacionada ao modo de criação, em que $100 \%$ (18) dos felinos reagentes eram errantes.

\section{REFERÊNCIAS}

BARATA, R.A.; FRANÇA-SILVA, J.C.; MAYRINK, W. et al. Aspectos da ecologia e do comportamento de flebotomíneos em área endêmica de leishmaniose visceral, Minas Gerais. Rev. Soc. Bras. Med. Trop., v.38, p.421425, 2005.

BASTOS, M.S.; BERNER, A.; RAMOS, E.R.P. Avaliação do grau de hemólise e sua interferência em análises bioquímicas de amostras obtidas por diferentes técnicas de coleta de sangue venoso. In: MOSTRA INTERNA DE TRABALHOS DE INICIAÇÃO CIENTÍFICA, 5., 2010, Maringá. Anais... Maringá: Cesumar, 2010.

BRASIL. Ministério da Saúde. Secretaria de Vigilância em Saúde. Departamento de Vigilância das Doenças Transmissíveis. Manual de vigilância da leishmaniose tegumentar. Brasília: Ministério da Saúde, 2017. 189p.

BRASIL. Ministério da Saúde. Secretaria de Vigilância em Saúde. Departamento de Vigilância Epidemiológica. Manual de vigilância e controle da leishmaniose visceral. Brasília: Ministério da Saúde, 2006. 120p. (Série A. Normas e Manuais Técnicos). 
BRIANTI, E.; FALSONE, L.; NAPOLI, E. et al. Prevention of feline leishmaniosis with an imidacloprid $10 \%$ /flumethrin $4.5 \%$ polymer matrix colar. Parasitol. Vectors, v.10, p.334, 2017.

CALDART, E.T.; FERREIRA, F.P.; MATTOS, A.M.R.N.M. et al. Diagnóstico sorológico de Leishmania spp. em felinos e reação cruzada/coinfecção com Toxoplasma gondii e Trypanosoma spp. Rev. Ciênc. Vet. Saúde Pública, v.3, p.166-169, 2016.

CAN, H.; DÖŞKAYA, M.; ÖZDEMIR, H.G. et al. Seroprevalence of Leishmania infection and molecular detection of Leishmania tropica and Leishmania infantum in stray cats of İzmir, Turkey. Exp. Parasitol., v.167, p.109-114, 2016.

CARDOSO, L.; LOPES, A.P.; SHERRY, K. et al. Low seroprevalence of Leishmania infantum infectious in cats from northern Portugal based on DAT and ELISA. Vet. Parasitol., v.174, p.3742, 2010.

CHATZIS, M.K.; LEONTIDES, L.; ATHANASIOU, L.V. et al. Evaluation of indirect immunofluorescence antibody test and enzyme-linked immunosorbent assay for the diagnosis of infection by Leishmania infantum in clinically normal and sick cats. Exp. Parasitol., v.147, p.54-59, 2014.

CIDADES: Bauru, São Paulo. Rio de Janeiro: IBGE, 2016. Disponível em: $<$ http://cidades.ibge.gov.br/xtras/perfil.php?codm un=350600 > . Acessado em: 18 maio 2017.

COSTA, T.A.C.; ROSSI, C.N.; LAURENTI, M.D. et al. Ocorrência de leishmaniose em gatos de área endêmica para leishmaniose visceral. Braz. J. Vet. Res. Anim. Sci., v.47, p.213-217, 2010.

DESJEUX, P. Leishmaniasis: current situation and new perspectives. Comp. Immunol. Microbiol. Infect. Dis., v.27, p.305-318, 2004.

GARRIDO, J.M.C.B.G. Contribuição para o estudo da prevalência da infecção por Leishmania infantum em gatos domésticos e errantes nos distritos de Lisboa e Viseu. 2012. 115f. Dissertação (Mestrado em Medicina Veterinária) - Faculdade de Medicina Veterinária, Universidade Técnica de Lisboa, Lisboa, PT.
GOVERNO DO ESTADO DE SÃO PAULO. Secretaria de Economia e Planejamento. Instituto Geográfico e Cartográfico. Região Administrativa de Bauru, 2016.

GUIMARÃES, M.C.; GIOVANNINI, V.L.; CAMARGO, M.E. Antigenic standardization for mucocutaneous leishmaniasis immunofluorescence test. Rev. Inst. Med. Trop. São Paulo, v.16, p.145-148, 1974.

MANUAL of diagnostic tests and vaccines for terrestrial animals. 6.ed. Paris: Office International des Epizooties/World Organisation for Animal Health, 2008.

MAROLI, M.; PENNISI, M.G.; MUCCIO T. et al. Infection of sandflies by a cat naturally infected with Leishmania infantum. Vet. Parasitol., v.145, p.357-360, 2007.

MARTÍN-SÁNCHEZ, J.; ACEDO, C.; MUÑOZ-PEREZ, M. et al. Infection by Leishmania infantum in cats: epidemiological study in Spain. Vet. Parasitol., v.145, p.267-273, 2007.

MARZOCHI, M.C.A.; COUTINHO, S.G.; SABROZA, P.C. et al. Reação de imunofluorescência indireta e intradermorreação para leishmaniose tegumentar americana em moradores na área de Jacarepaguá (Rio de Janeiro). Estudo comparativo dos resultados observados em 1974 e 1978. Rev. Inst. Med. Trop. São Paulo, v.22, p.149-155, 1980.

MONTOYA, A.; GARCÍA, M.; GÁLVEZ, R. et al. Implications of zoonotic and vector-borne parasites to free-roaming cats in central Spain. Vet Parasitol., v.251, p.125-130, 2018.

NAVARRO, J.A.; SÁNCHEZ, J.; PEÑAFIELVERDÚ, C. et al. Histopathological lesions in 15 cats with leishmaniosis. J. Comp. Pathol., v.143, p.297-302, 2010.

NOÉ, P.; DOMINGOS, S.L.; OSHIRO, E.T. et al. Detection of Leishmania chagasi in cats (Felis catus) from viscera leishmaniasis endemic area in Brazil. Ciênc. Anim., v.25, p.3-14, 2015.

OTRANTO, D.; NAPOLI, E.; LATROFA, M.S. et al. Feline and canine leishmaniosis and other vector-borne diseases in the Aeolian Islands: pathogen and vector circulation in a confined environment. Vet. Parasitol., v.236, p.144-151, 2017. 


\section{Camprigher et al.}

PARANHOS-SILVA, M.; FREITAS, L.A.R.; SANTOS, W.C. et al. A cross-sectional serodiagnostic survey of canine leishmaniasis due to Leishmania chagasi. Am. J. Trop. Med. Hyg., v.55, p.39-44, 1996.

PENNISI, M.G.; PERSICHETTI, M.F. Feline leishmaniosis: is the cat a small $\operatorname{dog}$ ? Vet Parasitol., v.251, p.131-137, 2018.

QUINNELL, R.J.; KENNEDY, L.J.; BARNES, A. et al. Susceptibility to visceral leishmaniasis in the domestic dog is associated with MHC class II polymorphism. Immunogenetics, v.55, p.23-28, 2003.

SIMÕES-MATTOS, L.S.; MATTOS, M.R.F.; TEIXEIRA, M.J. et al. The susceptibility of domestic cats (Felis catus) to experimental infection with Leishmania braziliensis. Vet. Parasitol., v.127, p.199-208, 2005.

SOLANO-GALLEGO, L.; LLULL, J.; RAMOS, G. et al. The Ibizian hound presents a predominantly cellular immune response against natural Leishmania infection. Vet. Parasitol., v.90, p.37-45, 2000.

SOLANO-GALLEGO, L.; RODRÍGUEZCORTÉS, A.; INIESTA, L. et al. Cross-sectional serosurvey of feline leishmaniasis in ecoregions around the northwestern Mediterranean. Am. J. Trop. Med. Hyg., v.76, p.676-680, 2007.

SZARGIKI, R.; CASTRO, E.A.; LUZ, E. et al. Comparison of serological and parasitological methods for cutaneous leishmaniasis diagnosis in the state of Paraná, Brazil. Braz. J. Infect. Dis., v.13, p.47-52, 2009.

VITA, S.; AGUZZI, I.; PETROTTA, E. et al. Feline leishmaniasis and ehrlichiosis: serological investigation in Abruzzo region. Vet. Res. Commun., v.29, p.319-321, 2005. 